\title{
Corrigendum to "Holocene climate variability on millennial scales recorded in Greenland ice cores" published in Nonlin. Proc. Geophys., 12, 345-352, 2005
}

\section{A. Witt and A. Y. Schumann}

Nonlinear Dynamics Group, Physics Department, University of Potsdam, PB 601553, 14469 Potsdam, Germany

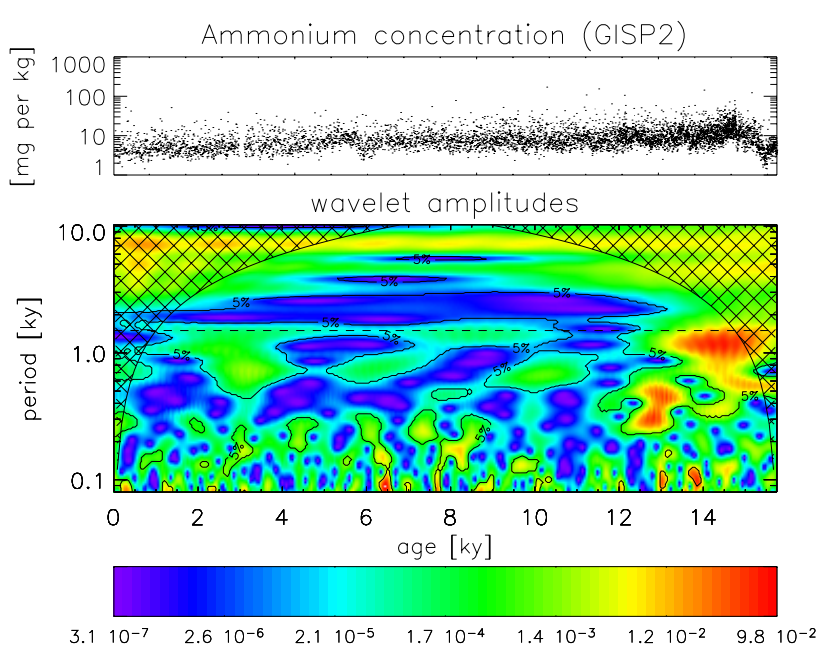

The authors regret, that Fig. 3 of the above paper presents the wrong age interval (the past $50 \mathrm{kys}$ instead of the past $15.7 \mathrm{kys})$.

Fig. 3. The GISP2 ammonium concentration record (top) and its wavelet amplitudes (bottom). Contoured regions contain periodic shares significantly different from red noise assuming an error probability of $5 \%$. 